\title{
Aspectos culinarios y farmacéuticos del ajo
}

\author{
María del Carmen Francés Causapé ${ }^{1}$
}

Resumen: Francés Causapé, M. C. 2012. Aspectos culinarios y farmacéuticos del ajo. Bot. Complut. 36: 131-137.

El ajo, bulbo de la planta Allium sativum L., a la que el refranero español alude frecuentemente, ha sido comúnmente utilizado desde tiempos remotos por sus propiedades extraordinarias tanto como alimento como medicamento. No es extraordinario por ello que el refranero español haga muchas alusiones a él. Su valor nutricional se pone de manifiesto no sólo a través de los pintores de bodegones de los siglos XVII y XVIII sino también por su utilización como componente de alimentos españoles tan tradicionales como son: las sopas de ajo, el gazpacho y diversas salsas. Su valor terapéutico fue conocido desde la antigüedad por la gente rústica siendo utilizado como antídoto por lo cual era denominado «triaca de los labradores», pero sobre todo, fue empleado como antiséptico y formó parte de composiciones farmacéuticas como el «vinagre antiséptico» 0 «vinagre de los cuatro ladrones», preparación medicinal muy afamada durante los siglos XVII y XVIII; y aún hoy en día forma parte de preparaciones farmacéuticas homeopáticas.

Palabras clave: ajo, nutrición, terapéutica, alimentos, medicamentos, refranes españoles, bodegones españoles.

Abstract: Francés Causapé, M. C. 2012. Culinary and pharmaceutical aspects of garlic. Bot. Complut. 36: 131-137.

The garlic is the bulb of the Allium satiivum L. plant to that the Spanish collection of proverbs alludes frecuently to it. It has been commonly used a long time ago because it has properties of a great value like food and medicine. Its nutritional value is revealed not only across the nature painting of the XVIIth and XVIIIth centuries but also because it is an usual component of Spanish traditional foods like the soups of garlic, the "gazpacho" and divers sauces. Its therapeutic value was known from the old times as antidote by what it was knew as the "theriac of the farmers". But it was mainly used as antiseptic to that it was part of pharmaceutical compositions as one very famous in XVIIth and XVIIIth centuries medicine named "Antiseptic vinager" or "Vinager of four thieves". And also nowadays it is used as ingredient to prepare different prescriptions for homeopathy medicine.

Key words: garlic, nutrition, therapeutic, foods, medicines, Spanish proverbs, Spanish nature paints.

El ajo común es el bulbo de la planta Allium sativum L., de la familia Liliáceas, que se tiene por una de las plantas más antiguas del mundo. El término Allium se debe al poeta latino Virgilio y podría derivar de la voz celta all que significa caliente, picante; y de seminativum que significa semilla.

Origen. Se trata de una planta originaria de Asia Central. Se cultivaba en China unos 4000 años antes de Cristo $y$ en Mesopotamia unos 3000 años antes de Cristo, pasando después a Egipto de donde se supone que se extendió su uso propagándose al área mediterránea. Según Herodoto (siglo V antes de Cristo), a quien se debe por primera vez la descripción del mundo antiguo, en su obra Historiae, la primera escrita en prosa griega, describe cómo los esclavos encargados de la construcción de la pirámide de Gizeh eran alimentados con ajos y, en efec- to, los jeroglíficos egipcios muestran a los obreros de las pirámides comiendo ajos pues se les atribuían propiedades fortificantes y vigorizantes. En la tumba de Tutankamón se encontraron bulbos de ajos y los sacerdotes egipcios ya ofrendaban esta hortaliza a sus dioses. El ajo se utilizó como alimento por hebreos, fenicios, griegos y romanos.

En Grecia se atribuían propiedades mágicas al ajo y se le dedicó al dios de la guerra Ares. Homero en la Odisea, poema épico del siglo VIII antes de Cristo, refiere que cuando Circe convirtió en cerdos a los compañeros de Ulises, éste pudo sustraerse a tal hechizo gracias al ajo que recibió del dios Hermes, protector de los viajeros y patrón de los atletas. El hecho de atribuírsele propiedades mágicas hizo que se le utilizara, quemado con otras hierbas, y siguiendo un ritual para ahuyentar los malos espíritus. Los

\footnotetext{
${ }^{1}$ Departamento de Farmacia y Tecnología Farmacéutica, Facultad de Farmacia, Universidad Complutense de Madrid, E-28040 Madrid, España.frances@farm.ucm.es

Para Esther Fuertes, compañera de estudios y amiga entrañable, como homenaje a su intensa actividad docente e investigadora.

Recibido: 31 octubre 2011. Aceptado: 15 noviembre 2011.
} 
atletas olímpicos masticaban ajos antes de competir para excitar su valor y como vigorizante.

En Roma el dios griego Ares fue identificado con Marte, dios de la guerra y de la agricultura, por lo que los ajos eran consumidos por sus propiedades mágicas por los soldados para infundirles valor y vigor por lo que constituyeron el símbolo de las legiones puesto que era la principal provisión que portaban. También los gladiadores eran muy aficionados a consumir ajos para estimularles en los combates por las propiedades excitantes que se les atribuían. Quinto Horacio Flaco, el principal poeta lírico latino del siglo I refiere en sus Epodos que los que criaban gallos de pelea les daban de comer ajos porque así los animales se volvían más animosos y corajudos.

En Europa, en la Edad Media los ajos se consumían en exceso por los aldeanos y por la gente menesterosa y se decía que olía a ajo «de un modo repugnante». A finales del siglo XV, los españoles introdujeron el ajo en el continente americano donde se aclimató muy bien, en particular en Las Antillas.

La importancia del ajo como elemento culinario lo puso de manifiesto el pintor sevillano Diego Velázquez en varios cuadros, de tema entre profano y sacro, como son La Mulata, que se expone en la National Gallery de Dublín (Irlanda), que tal vez sea la primera obra conocida del pintor, realizada entre 1617 y 1618, en que se representa el momento en el que una criada se acerca a una mesa de cocina en la que, entre diversos objetos se observa una cabeza de ajos. En la escena religiosa Jesús se encuentra cenando con los discípulos de Emaús. En el cuadro Cristo en casa de Marta y María, realizado en 1619 que se encuentra en la National Gallery de Londres (Gran Bretaña), en el que en primer término se representa a una joven, que está trabajando en la cocina, machaca con la mano derecha en un mortero de bronce posiblemente los ajos que se encuentran sobre la mesa. Francisco Barreda en su obra dedicada a las cuatro estaciones, que se conserva en el $\mathrm{Mu}$ seo de Bellas Artes de Sevilla, en la representación del Otoño (c. 1638), que gira alrededor de la vendimia, pintó en la parte superior izquierda, sobre el estrado, varias ristras de ajo.

La importancia del ajo en la cocina española se pone de manifiesto en los pintores de bodegones del siglo XVII y XVIII que en nuestro país tuvieron una personalidad singular puesto que, sin temor a ser menospreciados, reflejaron en sus naturalezas muertas los diversos elementos utilizados en las cocinas y despensas españolas. Así por ejemplo en la segunda mitad del siglo XVII Antonio Pereda en su Bodegón de cocina pintó entre cacharros, frutas y hortalizas varias cabezas de ajo. En el siglo XVIII
Luis Egidio Meléndez, a través de la magnífica colección de bodegones debidos a su pincel, que se conserva en el Museo del Prado; nos muestra los utensilios utilizados en las cocinas de la época así como las maneras de comer a través de los productos alimenticios que se reflejan en sus lienzos, así por ejemplo en Bodegón con chupetón, pan, cuenco de comida y recipientes de cocina en el que en primer término se observa una cabeza de ajos; en Bodegón con perdices, cebollas, ajos y recipientes pintó una cabeza de ajos y varios dientes de ajo sueltos; en Bodegón con besugos y naranjas a la derecha, tras la cola del pescado, figura una cabeza de ajos; en Bodegón con trozo de carne también a la derecha y en primer término se aprecia una cabeza de ajos y en Bodegón con ostras, huevos y un perol junto al plato de huevos pintó varios dientes de ajos.

Las propiedades nutritivas del ajo se plasman en el refranero español que sentencia:

- Quítale al labriego el ajo, y lo conocerás en su trabajo.

- Quítale el ajo y muerto has al aldeano.

- Comer ajo y beber vino no es desatino.

- Ajo, sal y pimiento, y lo demás es cuento.

- Con pan y ajo crudo se anda seguro.

- Ajo crudo y vino puro pasan el puerto seguro.

Asimismo sus propiedades vigorizantes y estimulantes se reflejan en los siguientes refranes españoles:

- En tiempo nevado, un ajo vale lo que un caballo.

- Al que trabaja y anda desnudo, ajo y vino puro. trabajo).

- Pan, vino y ajo, crudos, hacen andar al mozo agudo (en el

Denominación. Ajo es el nombre vulgar en castellano pero en otras lenguas se le dan otras denominaciones, así: catalán: all; vasco: beratz, baratxuni; gallego y portugués: alho; francés: ail; inglés: garlic, ramson; alemán: knoblauch; italiano: aglio; holandés: knoflook, look; chino: da suan; japonés: taisan; hindú: lasan; hebreo: sum; sánscrito: lasuna, ugragandha; persa: sir.

Producción. Los mayores productores de ajo del mundo se encuentran centralizados en: 1 . Asia: $87 \%$, siendo China el principal productor del mundo. 2. Europa: $6 \%$ que se produce en España, Francia e Italia, países a los que se anexionan Egipto y Turquía por la proximidad geográfica. 3. Norteamérica: 3\% que se produce en Méjico y Estados Unidos de América. En este último la localidad de Gilroy, en California, se autoproclama como «la capital mundial del ajo». 4. Sudamérica: 4\% que se produce en Brasil, Argentina y Chile.

En España, hay cinco zonas de producción perfectamente definidas: Castilla-La Mancha, Andalucía, Castilla-León, Madrid y Zaragoza. En Castilla-La Mancha, Cuenca es la provincia que mayor superficie dedica en Es- 
paña al cultivo del ajo y en concreto la comarca de Las Pedroñeras, que concentra un $40 \%$ de la producción del país, con cerca de la mitad de las hectáreas plantadas, y que además acoge la Feria Internacional del Ajo que viene celebrándose desde 1973. En Andalucía, son las provincias de Granada y Córdoba las que mayor interés dedican al cultivo del ajo, en particular la localidad cordobesa de Montalbán, con una producción del 34\% en el país. El resto de la producción se reparte entre Castilla-León, en concreto en el municipio burgalés de Castrojeriz, localidad que celebra la Feria del Ajo desde 1979, fecha en la que se ha recuperado la que se celebraba en la Edad Media; Madrid y Zaragoza en que las localidades de Chinchón y Arándiga respectivamente se dedican al cultivo de esta hortaliza.

Variedades. Además del ajo común existen diversas variedades como el ajo pardo que tiene su origen en Dinamarca y al que se le conoce como «ajo de España» que se cultiva en el Levante español donde popularmente se le conoce como «ajo murciano» y cuya carne es más jugosa y más picante. En España las dos únicas variedades que se exportan son el ajo morado de Jaén y de Castilla-La Mancha y el ajo blanco de Córdoba y Chinchón que vienen a representar el $96 \%$ y el $4 \%$ del total de los envíos realizados al extranjero. Hay que tener en cuenta que el ajo autóctono de Las Pedroñeras tiene la denominación específica de «Ajo morado de Las Pedroñeras» que le diferencia del resto de las variedades existentes en el mercado y que supone un reconocimiento de que es, sin lugar a dudas, el de mayor calidad. Los principales exportadores de ajos son: China, Argentina, España y Méjico. Nuestro mayor competidor en el mercado es el ajo chino ya que su precio es inferior y esta circunstancia influye en el comercio mundial de esta hortaliza induciendo a su compra.

Valor nutricional (Tabla 1). Para que el ajo mantenga su valor nutricional después de la recolección, los bulbos secos y limpios de tierra, se enristrarán y se coloca- rán bajo techo, en un lugar seco y ventilado para que acaben de perder la humedad que aún pudieran alojar.

Aspectos culinarios. El ajo ha sido utilizado en la preparación de algunos de los alimentos más tradicionales de nuestro país, así por ejemplo: la sopa de ajo, el gazpacho $\mathrm{y}$ varias salsas para aderezar algunos platos.

La sopa de ajo: se trata de uno de los platos nacionales de España. Aunque es de origen humilde, sin embargo, es uno de los más típicos y populares de la gastronomía española. Tiene la ventaja de poderse consumir en todas las estaciones del año y en todas las etapas de la vida.

La receta de la sopa de ajo es antiquísima, es sencilla, práctica, nutritiva y económica. Consta de pocos ingredientes: agua caliente, pan duro, ajo, pimentón y sal. Se prepara poniendo aceite en la sartén y friendo tres o cuatro ajos picados, cuando están bien dorados, se agrega una cucharada de pimentón y, antes de que se ennegrezca, se añade el pan bien cortado a rebanadas o bien algo tostado, después el agua hirviendo y la sal. Existen muchas variantes como la sopa castellana en la que el toque final suelen ser los huevos que se pueden añadir para ser escalfados o bien para ser rotos en la superficie de la sopa y removiendo la yema en el interior de la sopa, con una cuchara de palo, quedando la clara formando una especie de hilos blancos. Se debe servir muy caliente y en cazuelas de barro para mantener la temperatura. En la sopa de ajo seca se cuece tanto que el caldo se consume casi totalmente. En la sopa de ajo soriana se añade un puñado de setas senderuelas. La sopa de ajo a la andaluza consiste en utilizar el agua de cocción de una coliflor. La sopa de ajo a la navarra se prepara con pimientos choriceros en lugar de emplear pimentón.

Nuestros literatos más o menos bohemios del siglo pasado fueron grandes consumidores de sopa de ajo. Una letrilla refranera del Bajo Aragón exalta el valor culinario de la sopa de ajo pues dice así:

Tabla 1

Valor nutricional en 100 gramos de producto comestible

\begin{tabular}{lcccc}
\hline & Vitaminas & Minerales & Oligoelementos & $\begin{array}{c}\text { Principios activos: } \\
\text { aceite esencial }\end{array}$ \\
\hline Calorías: $98-139 \mathrm{kcal}$ & B1: $0,2 \mathrm{mg}$ & Calcio: $10-24 \mathrm{mg}$ & Selenio & Bisulfuro de alilo \\
Agua: $61 \mathrm{~g}$ & B2: $0,11 \mathrm{mg}$ & Hierro: $1,7-2,3 \mathrm{mg}$ & Germanio & Trisulfuro de alilo \\
Proteínas: $4-6,4 \mathrm{~g}$ & B3: $0,7 \mathrm{mg}$ & Fósforo: $40-195 \mathrm{mg}$ & & Tetrasulfuro de alilo \\
Lípidos: $0,5 \mathrm{~g}$ & C: $9-18 \mathrm{mg}$ & Potasio: $540 \mathrm{mg}$ & & Bisulfuro de alilpropilo \\
Glúcidos: $20 \mathrm{~g}$ & & & Aliína \\
& & & & Alicina \\
\hline
\end{tabular}




$\begin{array}{ll}\text { Siete virtudes } & \text { y digerir. } \\ \text { tienen las sopas: } & \text { nunca enfadan, } \\ \text { quitan el hambre, } & \text { siempre agradan } \\ \text { y dan sed poca, } & \text { y crían la cara } \\ \text { hacen dormir } & \text { colorada. }\end{array}$

Hay que tener en cuenta que para el pueblo español tener la cara colorada ha sido siempre señal cierta de buena salud.

Leopoldo de Luis (1918-2005), representante de la poesía de postguerra, fue republicano y sufrió prisión en Ciudad Real y Ocaña. Dedicó el poema Aquellas sopas de ajo que se incluyó en el poemario «Con los cinco sentidos» de la Colección Fuendetodos que se publicó en Javalambre (Zaragoza) en 1970 y que dice así:

Ha llegado el sabor de las sopas de ajo
en el amanecer de los presidios.
Por la tristeza de las galerías
hay un rumor de pies y de bocas hambrientas
hacia los patios de las formaciones
No es un espejo el alba macilenta
por la tierra entre llanos
que aún cuartea la helada.
No nos vemos el hueco de la boca
hacia el sabor del odio
digo el de sopas de ajo entre fusiles.

En el año 2001 la Profesora María Luz Escribano Pueo, Catedrática del Departamento de Didáctica de Lengua y Literatura de la Universidad de Granada, ha publicado un relato titulado Sopas de ajo. Memoria de una niñ. Una de las partes de la obra está dedicada a las Sopas de ajo y es la que le da titulo a la obra. La autora recrea en ella cómo durante los años de la Guerra Civil, en las duras noches de Castilla, su tía Dolores, para combatir el hambre y el frío, preparaba sopas de ajo para cenar según «la sabiduría ancestral de una cocina» y va desgranando cómo los niños de la casa contemplaban el buen hacer de la tía con expectación pues dice: «Vamos a cenar sopas de ajo, hervidas o turradas, con el rojo pimentón flotando en la superficie rosada de los platos (...) Los niños, refugiados en el amable calor de la cocina, vemos cómo van subiendo las laminillas finísimas de pan en la cazuela, y cómo luego hierven, muy despacio, aromando la estancia, destilando un lentísimo consuelo para el hambre».

El gazpacho: en el año 2007 en la revista Schironia las Dras. $\mathrm{M}^{\mathrm{a}}$ Esperanza Torija Isasa y $\mathrm{M}^{\mathrm{a}}$ Cruz Matallana González publicaron un documentado artículo sobre «El gazpacho andaluz y su interés nutritivo» en el que dan cuenta de los diferentes tipos de gazpacho andaluces, tanto fríos como calientes y de su gran aporte energético pa- ra el organismo debido al pan y al aceite, proteico por la guarnición empleada así como vitamínico, principalmente de la vitamina $\mathrm{C}$, y de elementos minerales gracias a las hortalizas y que son tan necesarios en nuestra dieta.

El origen del gazpacho, que en realidad es una sopa fría, no se conoce pero sí podemos decir que es un antiguo plato perviviente en la gastronomía de Andalucía. Ya en época romana, el poeta Publio Virgilio Marón, que vivió en el siglo I antes de Cristo, mencionaba en la Égloga II que Testilis majaba ajos, serpol y hierbas aromáticas para los fatigados y sedientos segadores. Se trata fundamentalmente de una emulsión de aceite de oliva en agua fría a la que se añaden pan mojado en agua, vinagre, ajos y sal. Estos ingredientes son majados en un almirez, después se pasan por un colador y es dispuesto el líquido resultante en un cuenco de barro cocido para mantener mejor su frescura. Se sirve a los comensales en cuencos más pequeños de barro y como guarnición, y a gusto de cada uno, se utilizan los ingredientes troceados. En el siglo XVI se incorporaron al gazpacho las verduras como el pepino y en el siglo XVII, los dos originarios del continente americano, como el pimiento y el tomate.

El gazpacho era un plato cuyo consumo era propio de los labradores en Sevilla y en verano, ya que por sus propiedades nutritivas saciaba su apetito además de ser refrescante, lo que les ayudaba a soportar las elevadas temperaturas que se alcanzaban en esa estación del año. Por esta razón este plato popular recibió el nombre de gazpacho andaluz o gazpacho sevillano.

Miguel de Cervantes Saavedra cita en El Quijote con menosprecio el gazpacho que consumía el vulgar Sancho; sin embargo el escritor del Siglo de Oro Vicente Gómez Martínez-Esquivel, en su novela picaresca Relaciones de la vida del escudero Marcos de Obregón (1618) pone en boca de su personaje que el gazpacho es la «cosa más sabrosa (que) he visto en mi vida». A mediados del siglo XIX la andaluza Eugenia de Montijo, esposa de Napoleón III, puso de moda el gazpacho en la corte francesa. A finales del siglo XIX los escritores como Juan Valera, José Augusto Trinidad Martínez-Ruiz, conocido con el seudónimo de Azorín, ensalzaron el gazpacho como un alimento saludable y, en el siglo XX; el Dr. Gregorio Marañón expuso su admiración por la sabiduría popular que a través de los siglos ha permitido alimentarse a los agricultores con él para soportar las rudas labores del campo bajo un sol canicular.

El gazpacho andaluz ha pasado contemporáneamente de ser un plato humilde a ser un plato estrella de la cocina nacional española en el verano, a la misma altura que la sopa castellana y la paella valenciana. Hay muchas va- 
riantes del gazpacho en nuestro país, así el salmorejo de Córdoba, que es más espeso y lleva guarnición de jamón serrano y huevo cocido de codorniz; el ajoblanco de Granada y Málaga, que lleva almendras en lugar de tomate, y no lleva vinagre, celebrándose en el pueblo malagueño de Almáchar todos los años el 2 de septiembre la fiesta del ajo blanco. La porra antequerana que puede llevar atún, el zoque malagueño que lleva zanahoria, el pimporrete de la localidad cordobesa de Almedinilla es el único gazpacho que no lleva aceite.

Entre los gazpachos calientes el carnerete de Córdoba, es un plato a base de patatas entre cocidas y hervidas, que se prepara con ajos y pan frito pero sin carne, a pesar de su nombre; el gazpachuelo malagueño a base de patatas, ajos, caldo de pescado y mayonesa; el arranque roteño o gazpacho de Cádiz es un plato que está entre el gazpacho y el ajo caliente; y el gazpacho del huevo frito de Extremadura, preparado con verduras y en el que en el aceite de freír los ajos se fríe además el huevo. Este gazpacho extremeño se usó, según creencia popular, para abrir el apetito a los enfermos y personas inapetentes. En general se puede decir que una creencia popular, muy generalizada, es que las comidas preparadas con vinagre son las más apetitosas para personas inapetentes, enfermas y pobres de espíritu.

Las salsas: la más difundida para tomarla con carne asada 0 a la brasa, patatas asadas 0 hervidas, es la salsa alioli (del catalán alli, ajo, y oli aceite). Es una salsa de sabor fuerte a ajo cuyo origen se remonta a los romanos quienes la generalizaron por el mediterráneo: Italia, Francia y España. La fórmula original consiste en un majado de ajos ligado con aceite de oliva hasta formar una crema. Una variedad es la salsa al ajo arriero que se prepara machacando ajo con sal y agregando después limón y aceite.

Aspectos farmacéuticos. El ajo ha sido empleado en terapéutica desde la más remota antigüedad. El Beroso, del siglo III antes de Cristo, en su obra Historia de Babilonia relata que en Mesopotamia se recomendaba mascar ajo para combatir la halitosis, utilizaban un fomento con ajos machacados como analgésico en las distensiones musculares y preparaban una cerveza de ajo que administraban como un excelente antiparasitario.

En Egipto se taponaban las caries con una pasta hecha con ajos machacados y miel. Usaban el ajo para combatir las picaduras de los insectos y para controlar la extensión de las epidemias suministraban a sus esclavos hebreos grandes cantidades de ajos. En la tumba de Tutankamon se encontraron bulbos de ajos lo que demuestra la importancia que daban a los ajos tanto en la vida terrena como tras la muerte. En el Papiro de Ebers, 1550 años antes de Cristo, se incluyen 22 recetas confeccionadas a base de ajos; son formulaciones que servían para combatir las infecciones, faringitis, tumores y debilidad física.

En Grecia se conocían las propiedades desinfectantes del ajo pues Homero en la Iliada refiere cómo se utilizaba ajo majado, y ajo con vino, para curar las heridas. Llegó a ser un producto medicinal popular ya que a los enfermos intervenidos quirúrgicamente se les administraba una formulación medicinal analgésica elaborada con opio, ajos y vino.

En Roma los nobles bebían ajo mezclado con vino como antídoto contra posibles envenenamientos. Y a los soldados de las legiones romanas se les daban a comer unas gachas preparadas con cebada hervida, miel, granada y ajo para evitar las intoxicaciones que podían sobrevenirles al ingerir las aguas insalubres de los lugares por donde pasaban. Celso utilizaba los ajos contra la desnutrición y para tratar las fiebres intermitentes. El poeta romano Marcial elogiaba las virtudes afrodisíacas del ajo que estaban ligadas a las fiestas en honor a Ceres, la diosa de la agricultura, en las que se comían grandes cantidades de ajos como augurio de fertilidad. Dioscórides en su Materia medicinal, Libro II, capítulo 141, recomienda comer ajo como antiparasitario y diurético; beber ajos con vino como antídoto de las mordeduras de víboras y perros rabiosos y aplicar ajos majados en forma de emplasto sobre la herida. Señala otras aplicaciones como que comido crudo 0 cocido sirve para ablandar la tos, que su cocimiento bebido es útil como analgésico y hecho un cocimiento de ajos con orégano sirve bebido para matar liendres y piojos. La pasta confeccionada con ajos y aceitunas negras, que era conocida como Myttoton, comida, tenía propiedad diurética por lo que era útil en la hidropesía.

Asímismo Dioscórides aconseja el uso del ajo por vía tópica pues aplicado con aceite nardino servía para restituir los cabellos que hizo caer la tiña; y aplicado con aceite de oliva para curar las vesículas que salen por todo el cuerpo. Desde la más remota antigüedad el ajo se ha considerado como un «curalotodo» y se le han atribuido propiedades mágicas, quizá por su intenso aroma, pues se aconsejaba llevar ajos consigo para ahuyentar a los malos espíritus y el mal de ojo.

En la Edad Media el emperador Carlomagno dispuso que los ajos, entre otras plantas medicinales, se cultivaran en conventos, monasterios, castillos, etc., ... como «botica de reserva» en caso de enfermedad. Durante toda la Edad Media y el Renacimiento comer ajos era un recurso muy apreciado pues se consideraba que constituía un poderoso antídoto contra la peste. En el siglo XVI Ga- 
briel Alonso de Herrera, en su Agricultura General (1513), según la versión de José de Urrutia de 1790, en el Libro cuarto en que se ocupa de las Huertas, trata en el capítulo ocho de los ajos atribuyéndoles «muy singulares virtudes» como la de ser un excelente antídoto contra las mordeduras de animales venenosos si se bebe su zumo y si una vez majados se colocan sobre la herida; como antídoto de las aguas corruptas; como preventivo del aire corrupto, y por tanto de las enfermedades pestíferas, tanto si se comen ajos crudos por la mañana como si se bebe su zumo con vino; y decía que por esta razón los llamaban «la triaca de los labradores». Su zumo administrado en forma de clister era útil en la ciática y como antiparasitario para expulsar las lombrices del intestino. Los ajos comidos crudos se usaban contra la ictericia y ayudaban a «soldar las quebraduras de los niños», asados 0 cocidos ablandan la tos. Los ajos cocidos en vino y aceite, aplicados en fomento bajo el ombligo, se utilizaban como diurético. El médico renacentista Andrés Laguna no hace una especial referencia a las propiedades medicinales de los ajos, solamente comenta que iguales propiedades tienen los que crecen salvajes como los cultivados, aunque sí señala que constituían «familiar Theriaca de rusticas gentes» indicando el uso popular en medicina lo que equivalía a señalar que entre las clases sociales de la burguesía y nobleza ya estaba desterrado su uso. En la misma época, el gran botánico inglés John Gerard, en su General History of Plants (edición de 1633) cita entre las virtudes de los ajos: contraveneno, antitusígeno, diurético, antiflatulento, antihidrópico, contra las lombrices que padecen los niños, para la prevención de la peste y antiparasitario capilar.

El ajo formó parte de una fórmula medicinal que fue utilizada desde el siglo XVII y que se incorporó a la farmacopea española en el siglo XVIII, se trataba del Vinagre antiséptico o Vinagre de los cuatro ladrones en cuya fórmula, además del ajo, intervenían otras especies vegetales aromáticas como rosmarino, salvia y lavanda, entre otras, y la ruda utilizada como contraveneno que reforzarían las propiedades del ajo.

Dice la leyenda que cuando la ciudad francesa de Toulouse padeció una epidemia de peste, entre 1628 y 1631, cuatro ladrones se dedicaron a saquear las casas vacías porque habían muerto sus ocupantes. Fueron apresados y las autoridades, sorprendidos de que no hubieran contraído la enfermedad, les hicieron confesar bajo la promesa de liberarlos, qué habían estado tomando. Confiaron aquéllos su secreto que consistía en haber tomado un macerado de ajos y otras hierbas medicinales en vinagre. Cien años más tarde se repitió una situación similar en Marse- lla donde las autoridades obligaron a cuatro ladrones a enterrar a los apestados que habían fallecido, trabajo que nadie quería realizar, con la promesa de ser liberados si no se contagiaban de la enfermedad. También en esta ocasión hicieron uso del vinagre medicinal de ajo.

En el caso del ajo, las acciones medicinales que le ha atribuido la medicina popular han sido corroboradas posteriormente. El estudio científico de los principios activos de los bulbos de ajo se debe al alemán Wertheim, quien en 1844 extrajo de los ajos una sustancia de olor nauseabundo y propuso el nombre de alilo para designar a sus derivados. La propiedad antiséptica del ajo fue demostrada por Louis Pasteur en el siglo XIX, y se debe al médico suizo y Premio Nobel Artur Stool el haber dado a conocer que el poder bactericida del ajo se debía a su componente alicina, al que se debe además el típico olor a ajo. El médico militar alemán Willebrand utilizó el ajo durante la Primera Guerra Mundial, en el hospital donde trabajaba, como antidisentérico, por su actividad calmante y antidiarreica.

El bulbo de ajo contiene aceite esencial rico en compuestos sulfurados, siendo el más importante aliína, que mediante el enzima aliinasa, cuando se corta el ajo en estado fresco, se transforma en alicina, que es muy inestable. A estos compuestos debe el ajo su acción farmacológica como hipolipemiante, antimicrobiano y antihelmíntico. Está indicado por vía interna en la profilaxis de la ateroesclerosis, como antihipertensivo por actuar como un vasodilatador periférico, en el tratamiento de hiperlipemias, de infecciones del tracto respiratorio y de las vías urinarias; favorece la fluidificación de la sangre por su actuación como antiagregante plaquetario y por ello resulta beneficioso en las enfermedades coronarias; se emplea para reducir el colesterol, el estrés y la oxiuriasis. Se le atribuye una acción reguladora del sistema inmunitario por lo que podría prevenir el crecimiento tumoral. Se utiliza tópicamente como analgésico osteoarticular, en dermatomicosis, parodontopatías e hiperqueratosis.

La tercera edición de la Real Farmacopea Española de 2005 incluye al ajo entre sus monografías citando el polvo de ajo, obtenido a partir de los bulbos de ajo cortados y liofilizados, que se utiliza en la industria farmacéutica para la elaboración de cápsulas y perlas de aceite de ajo, jarabe concentrado de ajo, grageas, comprimidos y tabletas.

Como ejemplo, la cooperativa extremeña de Ajos de ACEUCHAL, sito en esta localidad de la provincia de Badajoz, y fundada en el año 2003, produce un ajo deshidratado para la fabricación de medicamentos y productos farmacéuticos de gran calidad, certificado por la norma ISO 
9001: 2000. También se incluyen en la Real Farmacopea Española los bulbos frescos de ajo para la obtención de preparaciones homeopáticas (4a ed., 2011).

De las creencias populares acerca de las virtudes medicinales del ajo nos da idea el refranero español que dice:

- A quien ajo come y vino bebe, ni la víbora puede.

- El ajo y el vino, atriaca es de los villanos.

- Ajo, cebolla y limón, y déjate de inyección.
Epílogo. Podemos decir por tanto que el ajo ha sido utilizado por el hombre y le ha acompañado en su devenir histórico desde la más remota antigüedad hasta la actualidad, pero ello ha sido siempre con el esfuerzo de su trabajo: cultivándolo, recolectándolo, preparándolo para su comercialización y consumo, tanto culinario como farmacéutico, cumpliéndose así «El destino del hombre» como sugiere el artista valenciano Paco de la Torre en su tabla de 1991, Fig. 18.

\section{BIBLIOGRAFÍA}

ARmiÑo, M. 1994. Diccionario de refranes: antología de refranes populares y cultos de la lengua castellana. Alderabán, Madrid.

ATERIDO FernÁNDEZ, A. 2002. El bodegón en la España del Siglo de Oro. Edilupa, Madrid.

BERDONCES, J. L. 2000. Cómo cura el ajo. RBA Libros S. A., Barcelona.

Bruneton, J. 2001. Farmacognosia, Fitoquimica. Zaragoza, Edit. Acribia.

BrunETON, J. 2004. Fitoterapia. Traducido por Ángel Villar del Fresno y Emilia Carretero Accame. Edit. Acribia, Zaragoza.

Campillo Álvarez, J. E. 2000. La alimentación saludable, según la sabiduría popular. Caja Rural de Extremadura, Badajoz.

CherRY, P. 1999. Arte y naturaleza: el bodegón español en el Siglo de Oro. Traducido por Ivars Barzdevics. Fundación de Apoyo a la historia del Arte Hispánico, Madrid.

DiosCóRIDES, P. 1566. Acerca de la materia medicinal y de los venenos mortiferos. Trad. e ilustr. por Andrés Laguna. Mathias Gast, Salamanca.

Escribano Pueo, M. L. 2001. Sopas de ajo. Memoria de una niña. Comares, Albolote (Granada).

FonT QueR, P. 2005. El Dioscórides renovado. Ediciones Península, Barcelona.

HeInerman, J. 1995. El ajo y sus propiedades curativas: Historia, remedios y recetas. $1^{\mathrm{a}}$ ed. Paidós Ibérica, Barcelona.

Herodoto 1987. Antología de Historia griega. Grupodis, Madrid.

HerRera, G. A. 1981. Agricultura General. Edición crítica de Eloy Terrón. Ministerio de Agricultura y Pesca, Madrid.

Herrero Hinojo, P. \& Francés Causapé, M. C. 1968. Estudio histórico del ajo. Bol. Soc. Esp. Hist. Fcia 19, 73: 1-11.
Krimaczer, P. 2010. Mesopotamia, la mitad de la historia humana, $1^{\text {a }}$ ed. Traducción de María Ruiz de Apodaca. Ariel, Barcelona.

LuIs, L. 1970. Con los cinco sentidos. Colección Fuendetodos. Javalambre, Zaragoza.

Miot, A. F. 1898. Histoire d'Hérodote suivi de la vie d'Homére. Fermin Didot, Paris.

Real Farmacopea Española $3^{\mathrm{a}}$ ed. 2005. Ministerio de Sanidad y Consumo, Agencia Española de Medicamentos y Productos Sanitarios, B.O.E., Madrid.

Real Farmacopea Española $4^{\mathrm{a}}$ ed. 2011. Ministerio de Sanidad, Política Social e Igualdad, Agencia Española de Medicamentos y Productos Sanitarios, B.O.E., Madrid.

SBARBI, J. M. 1875. El refranero general español. Impr. A. G. Fuentenebro, Madrid.

SendRa Esplá, X. 1990. Libro de la sabiduría popular. Eurograf, Alicante.

SoRIA, H. 1994. El ajo, entre la cocina y la farmacopea. Vida Rural 12: 32-33.

Thebusen, D. 1884. Ristra de ajos, formada con 6 cabezas. Tip. del Dr. Thebusen, Medina Sidonia.

TheBUSEn, D. 1886. Segunda ristra de ajos: compuesta de XIV cabezas. Impr. Ricardo Fé, Madrid.

Torija Isasa, M. E.; Matallana González, M. C.; SÁnchez Mata, M. C.; Verde Méndez, C. M.; Rodríguez RodríGUEz, E. M. \& Díaz Romero, C. 2007. El gazpacho andaluz y su interés nutritivo. Schironia 6: 22-27.

TRIAdó, J. R. 1982. El bodegón español en la pintura española del siglo XVII. Edic. Universitat de Barcelona, Barcelona.

Vanaclocha Vanaclocha, B.; Cañigueral Folcara, S. 2006. Fitoterapia. Vademécum de prescripción. Reimpresión de la $4^{\mathrm{a}}$ ed. Elsevier-Masson S. A., Barcelona. 